\title{
Uso e ocupação do corredor fluvial do rio Paraguai entre a foz do rio Jauru e a Fazenda Santo Antônio das Lendas, no município de Cáceres-MT
}

Este estudo objetivou avaliar a influência da geologia e do uso e ocupação da terra na composição granulométrica do sedimento da bacia do córrego Jacobina, em Cáceres-MT, Pantanal. Para tanto, a área foi dividida em três compartimentos considerando a geomorfologia local onde, uma coleta de sedimento de fundo e água para análise do sedimento em suspensão foi realizada nos períodos de cheia (fevereiro/2015) e de seca (julho/2015). O sedimento de fundo foi coletado através de uma draga do tipo Petersen e a água através de uma garrafa de Van Dorn. Dados relativos à profundidade e largura do canal, velocidade do fluxo da água e altura do barranco também foram mensurados. Os resultados demonstraram que o córrego Jacobina sedimenta partículas de granulometria mais grossa como areia grossa e média no fundo e o material mais fino tende a manter-se em suspensão nas seções 1 e 2. Na seção 3, o material depositado no fundo é de granulometria mais fina como areia fina e silte. Com relação às variáveis hidrodinâmicas a largura e a profundidade do canal diminuíram da estação chuvosa para a estação seca, diminuindo assim a velocidade do fluxo das águas e a vazão. Os dados demonstraram que o tipo e quantidade de sedimentos encontrados nas seções de coleta podem ser influenciados pelo material geológico e o tipo de uso da terra no entorno da bacia.

\section{Hydrodynamic and sedimentary composition on the Jacobina stream, municipality of Cáceres, MT, Pantanal}

\begin{abstract}
This study aimed to evaluate the influence of the geology and the land use and occupation on the granulometric composition of the sediment of the watershed Jacobina's Stream, in Cáceres, MT, Pantanal. Therefore, the basin was compartmentalized into high, medium and low course considering the geomorphological aspects, where sediment and water samples were collected in each site to analyze the granulometric particulates and suspended sediments on the water in the wet season (February/2015) and the dry season (July/2015). The sediment samples were collected using a Van Petersen dredger and for the water samples a Van Dorn Bottle were used. Data about the depth and width of the channel, water flow and the height of the shore were also performed. The results of the bottom sediment have been shown the Jacobina's stream deposit coarse particle size as such as coarse and medium sand and the fine material tends to remain suspended in both 1 and 2 sites. At the site 3 the deposited material it is fine as such as fine sand and silt. The width and the depth of the channel decreased from the wet to the dry season and the water flow consequently. The data have shown that the type and the amount of the sediment found at the sampled sites, might be influenced by the geologic material and the land use and occupation around at the basin.
\end{abstract}

Keywords: Fluvial Dynamic; Granulometry; Land Use and Occupation; Fluvial Geomorphology

Topic: Hidrogeografia

Reviewed anonymously in the process of blind peer.
Received: 02/02/2018

Approved: 20/05/2018
Loianne Curvo Gottardi Belote (1D)

Universidade do Estado do Mato Grosso, Brasil

http://lattes.cnpq.br/2601852566383960

http://orcid.org/0000-0003-3294-8026

loiannebelote@gmail.com

Celia Alves de Souza (iD

Universidade do Estado do Mato Grosso, Brasil

http://lattes.cnpq.br/4260661798494235

http://orcid.org/0000-0002-9068-9328

celiaalvesgeo@globo.com

Willian Cosme da Silveira de Paula (iD

Universidade do Estado do Mato Grosso, Brasil

http://lattes.cnpq.br/1547933332950541

http://orcid.org/0000-0002-7544-2247

willtmt15@gmail.com
Maria Aparecida de Souza (10

Universidade do Estado do Mato Grosso, Brasil

http://lattes.cnpq.br/6760195365262945

http://orcid.org/0000-0003-4916-2564

mariamia.souza8@gmail.com
Referencing this:

BELOTE, L. C. G.; SOUZA, C. A.; PAULA, W. C. S.; SOUZA, M. A.. Uso e ocupação do corredor fluvial do rio Paraguai entre a foz do rio Jauru e a Fazenda Santo Antônio das Lendas, no município de Cáceres-MT. Revista Ibero-Americana de Ciências Ambientais, v.9, n.1, p.249-264, 2018. DOI: http://doi.org/10.6008/CBPC2179-6858.2018.001.0018 


\section{INTRODUÇÃO}

Desde os tempos mais remotos, os cursos d'água são de grande importância para o desenvolvimento da espécie humana. Ao realizar suas conquistas por terra, o homem sempre procurava se estabelecer-se próximos a cursos d'água. Além disso, grandes civilizações surgiram e desenvolveram-se às margens de grandes rios, como os egípcios que prosperaram ao redor do impetuoso rio Nilo. A água doce é, portanto, um recurso da natureza renovável e vital aos povos de todas as épocas, utilizada para consumo humano e em atividades socioeconômicas, visto que as primeiras cidades surgiram nas margens dos lagos e rios (REBOUÇAS, 2006). Para Almeida e Pereira (2009), o acesso à água é fonte de poder desde a Antiguidade e, por esse motivo, também é o causador de vários conflitos.

A água é um recurso fundamental para a sobrevivência humana. Ao longo da história, os rios têm sido utilizados como vias de penetração para o interior, facilitando o crescimento de aglomerados urbanos e áreas cultivadas, contribuindo indiretamente para espelhar a forma como encontra-se a bacia hidrográfica (CUNHA, 2010). Para Guerra (2003), grande parte dos danos ambientais ocasionados pela ação humana ocorrem dentro de bacias hidrográficas.

Almeida e Pereira (2009) ressaltam que a ordenação do espaço ocupado por algumas civilizações tem influência direta da água, independentemente de a disponibilidade do recurso ser grande ou pequena. Percebe-se, aqui, a importância da água para o desenvolvimento da sociedade humana.

Tradicionalmente, os rios e canais têm sido estudados para que seja estabelecida uma relação com as mudanças e variáveis ambientais locais. Eles devem ser examinados, portanto, sob a ótica das bacias de drenagem, uma vez que refletem a forma de uso do solo e sua dinâmica. Além disso, as dimensões espaciais e temporais devem ser consideradas. Tais mudanças têm sido intensificadas devido à atuação antrópica desordenada sobre os ambientes, o que provoca extremas mudanças no solo e alteração da dinâmica fluvial (CUNHA, 2010).

A bacia de drenagem pode ser definida como a área abrangida por um rio ou como um sistema fluvial composto por um curso principal e seus tributários, exibindo peculiaridades que dependem de sua situação espacial (SUGUIO E BIGARELLA,1990).

O rio Paraguai, com $2.693 \mathrm{~km}$ de extensão em território brasileiro, constitui um dos rios mais importantes do Brasil. Seus principais afluentes são os rios Jauru, Cabaçal e Sepotuba, em sua margem direita; e os rios Cuiabá, Taquari, Miranda e Apa, em sua margem esquerda. O rio Paraguai percorre vasta área de planície, podendo ser considerado uma imensa bacia de recepção de águas e sedimentos, devido à sua forma de anfiteatro (SOUZA, 2004).

Segundo Silva et al. (2007), o rio Paraguai vem passando por transformações econômicas, proporcionadas pelos setores pecuarista e de turismo. Modificações do uso do solo e constantes dragagens realizadas ao longo do canal do rio estão provocando alterações significativas, podendo transformar o aporte de sedimentos no sistema e parte das características do rio. 
O rio Paraguai possui grande importância para o Pantanal. Segundo Souza (2004), o Pantanal exerce uma função reguladora do regime hídrico, provocando o retardamento e o escoamento da água. Assim, o sistema fluvial e a planície de inundação possibilitam a manutenção da complexidade paisagística e a biodiversidade no ambiente local. O estudo teve como objetivo verificar o uso e ocupação no corredor fluvial do rio Paraguai, entre a foz do rio Jauru e a fazenda Santo Antônio das Lendas.

\section{METODOLOGIA}

\section{Área de estudo}

A área de estudo compreende um trecho do rio Paraguai, entre a foz do rio Jauru e a fazenda Santo Antônio das Lendas (Morrinhos), no município de Cáceres, no Estado do Mato Grosso. O local encontra-se

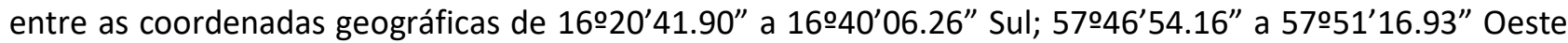
(Figura 1).

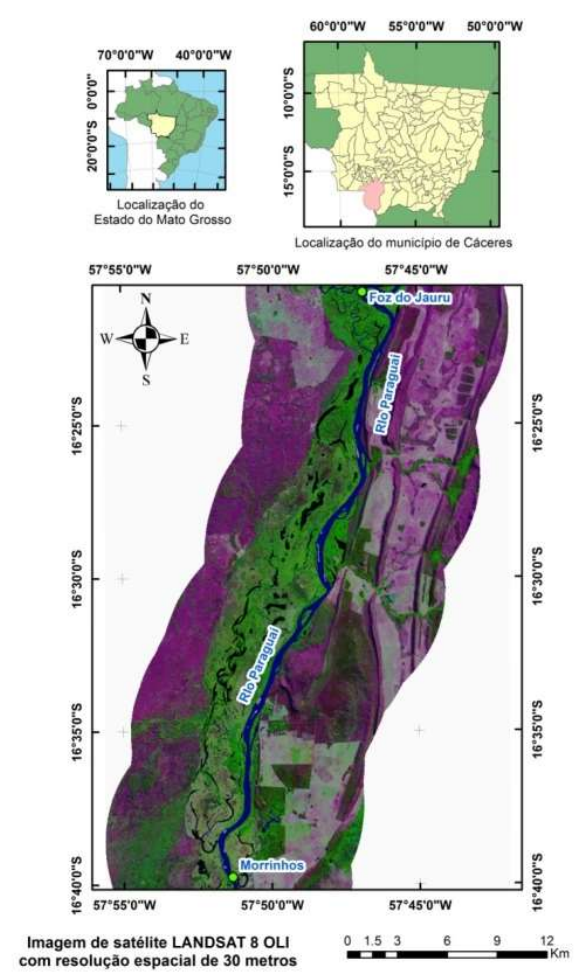

Figura 1: Localização da área de estudo, no município de Cáceres, MT.

Para realização desta pesquisa, foram efetuadas pesquisas bibliográficas e documentais com o intuito de verificar a navegabilidade no rio Paraguai e o surgimento das grandes fazendas situadas às margens do rio. Procurou-se, também, estabelecer relação com a evolução do processo de uso e ocupação ao longo do corredor fluvial. Foram utilizadas também as seguintes fontes: teses, dissertações, artigos, livros, relatórios, além de pesquisas na internet.

Por meio de imagens de satélites e trabalhos de observação no campo, foi realizado um mapeamento da área, o qual tem como objetivo verificar a evolução do uso da terra no período existente entre os anos de 1984 e 2015. 


\section{Coleta de Dados}

Além da pesquisa bibliográfica realizada em variadas fontes, foi realizado um mapeamento da área em dois anos distintos: 1984 e 2015. A escala temporal está diretamente correlacionada com os conceitos de equilíbrio e evolução da paisagem, cuja mudança está atrelada às variações que podem ocorrer ao longo de um período (IBGE, 2009).

Dessa forma, em um intervalo de tempo de 31 anos, foi feita a caracterização física da área em estudo. Inferiu-se a respeito dos padrões espaciais e temporais da dinâmica da área, a partir de produtos orbitais, elaborando mapas temáticos representativos do meio físico e identificando as variações espaçotemporais sobre uso e ocupação, tanto na planície quanto no canal.

Para referenciar o uso da terra, determinando as diferentes categorias de uso e ocupação, foram realizadas distintas ações, as quais estão elencadas abaixo:

Por meio de softwares SIG - Sistema de informação Geográfica foram realizadas as seguintes atividades: leitura, visualização, edição e agrupamento de dados espaciais para posterior análise e geração de mapas, informes e gráficos.

Para confecção dos mapas de localização e temáticos (área de estudo, uso e ocupação), foram utilizados os seguintes recursos: imagens do satélite Landsat 5 TM (1984) e do Landsat 8 OLI (2015), com resolução espacial de 30 metros; buffer de $7 \mathrm{~km}$ a partir do canal fluvial que compreende a foz do rio Jauru até a baía Morrinhos; georreferenciamento de Imagens do satélite Landsat 5 TM (1984) por registro, fazendo uso do Landsat 8 OLI (2015); segmentação de 7x7 pixels para o Landsat 5 TM (1984) e 10x10 para o Landsat 8 OLI (2015); classificação vetorial usando 100 (cem) amostras no processo de treinamento; exportação do vetor em formato .shp, posteriormente classificado de cores e layout.

Na finalização do banco de dados, foi utilizado o programa Software Open SourceSpring 5.2.7, disponível gratuitamente no site do INPE (Instituto Nacional de pesquisas Espaciais). A manipulação classificatória de cores em arquivo vetorial shp e o layout final dos mapas foram desenvolvidos pelo Software ArcGis $10.2 .1^{\circ}$.

O trabalho de campo deu-se a partir de visitas in loco por toda a extensão da área de estudo, a qual foi percorrida via terrestre e fluvial. Foram realizadas três visitações a campo, quando se pôde observar as atividades realizadas e as formas de uso e ocupação, tanto nas margens do rio quanto no próprio leito. Tais visitas ocorreram no ano de 2015 , durante o mês de setembro, período de estiagem.

\section{RESULTADOS E DISCUSSÃO}

Registros históricos mostram que a ocupação foi iniciada por povos indígenas. Ao longo do corredor fluvial do rio Paraguai existem vários sítios arqueológicos de extrema importância na contextualização histórica local.

O rio Paraguai exerceu forte influência no processo de ocupação do Estado de Mato Grosso. A cidade de Cáceres, que surgiu nesse contexto, possui toda a sua história interligada com o processo de navegação no rio Paraguai. Bindandi (2014) ressalta que nesse rio sempre trafegaram diversas embarcações em 
diferentes contextos históricos. Esse mesmo rio também foi o responsável pela viabilização da expansão lusobrasileira nas terras que estavam sob o domínio espanhol.

Nesse cenário, em 1778, surgiu o município de Cáceres, à margem esquerda do rio Paraguai, outrora denominado Vila Maria do Paraguai. Segundo Chaves (2011), após a assinatura do Tratado de Madrid, intensificou-se a política de povoamento e a demarcação de território português. Essas ações enquadravamse nos planos políticos, administrativo, econômico e populacional da Coroa Portuguesa, os quais originaram a porção atual da fronteira oeste do Brasil. O processo de ocupação no trecho de estudo aconteceu na margem esquerda do rio Paraguai, destacando as fazendas históricas: Ressaca, Barranco Vermelho e Santo Antônio das Lendas.

\section{Uso direto e impactos no rio Paraguai entre a foz do rio Jauru e a fazenda Santo Antônio das Lendas, no município de Cáceres}

Diversas atividades são desenvolvidas ao longo do corredor fluvial do rio Paraguai. O trecho de estudo possui características peculiares: existe, na margem esquerda, um controle estrutural; na margem direita, por sua vez, está presente uma planície de inundação, o que dificulta o desenvolvimento de determinadas atividades. A pecuária e o cultivo de soja são destaque na região. Além dessas, a navegação é contínua, devido ao turismo e à pesca. Para manter essas atividades durante todo o ano, a dragagem de manutenção torna-se cada vez mais necessária no trecho em questão.

\section{Navegação}

Atualmente, o número de embarcações que trafegam pelo rio Paraguai é expressivo. Dados da Marinha mostram, em Cáceres, a existência de 8.824 embarcações variadas, abrangendo desde barcos a remo até barcos motorizados com potências entre 3 e 350 HPs. Tais embarcações são registradas de acordo com sua Arqueação Bruta ( $A B)$, que é uma unidade de medida que se refere ao tamanho construído sob o casco da embarcação. A finalidade dessas embarcações é diversa: turismo, esporte recreio, pesca, transporte etc. É fato que embarcações maiores e de maior potência exercem um efeito negativo mais intenso.

As voadeiras, nome esse usado na região para embarcações mais rápidas, por exemplo, possui forte potência no motor, o que provoca ondas de maiores frequência e energia, fator que acelera o processo de erosão nas margens Além dessas, existem as embarcações acima de $100 \mathrm{AB}$, que são as maiores, como os barcos hotéis, e podem ocasionar o mesmo efeito. Silveira et al. (2015), em estudo sobre o turismo náutico realizado na Bacia do Alto Paraguai, trecho entre Cáceres e a foz do rio APA, alertam que, além dos barcos contribuírem para a erosão das margens dos rios, eles também podem ocasionar poluição da água através da emissão de combustível e óleo, trazendo danos à flora e à fauna.

Segundo dados obtidos pela Marinha, embarcações registradas acima de 10 AB (Arqueação Bruta), que são aquelas com maior potencial, somam um total de 99 veículos e são classificadas como: transporte de passageiros (35), transporte de carga (29), rebocador e empurrador (03), esporte/recreio (29), pesca (01), dragagem (02). 
Porém, o número de barcos motorizados menores (6 metros) é expressivo, registrando um total de 2.973 embarcações. Logo, pode-se inferir que tanto os barcos maiores quanto os menores podem estar contribuindo para a aceleração do processo de erosão das margens.

Embarcações podem ocasionar sérias consequências para o funcionamento de todo o ecossistema aquático, assim como na dinâmica fluvial do rio. Souza et al. (2012) diz que a navegação no rio Paraguai ocorre de forma desordenada.

Silva (2011), apesar de ter realizado um trabalho em um perímetro urbano da cidade de Cáceres, no rio Paraguai, distante da área de estudo desta pesquisa, constatou que o assoreamento no leito do rio está acelerando a cada ano. $\mathrm{O}$ autor atribuiu esse fato ao fluxo intenso das embarcações que provocam grandes ondas, as quais intensificam a erosão das margens do rio.

O turismo de pesca é uma das atividades mais desenvolvidas na região. Silveira et al. (2015) relatam que esse tipo de turismo no rio Paraguai vem sendo praticado principalmente por meio dos cruzeiros fluviais, realizados por barcos hotéis que circulam na região, garantindo o deslocamento de turistas e visitantes em escala local e regional. Sudré (2012) ressalta que, no Pantanal, na abrangência do município de Cáceres, o turismo desenvolve-se diante de sua vocação para as modalidades aliadas aos recursos naturais, como os segmentos turísticos de ecoturismo, turismo rural, de aventura, ecológico, científico, cultural e de pesca, o qual se destaca pela grande atratividade local.

Diante isso, surgiram na cidade diversos barcos hotéis, embarcações luxuosas que oferecem todo conforto aos turistas, proporcionando serviços e produtos diferenciados, tais como: iscas, utensílios de pesca, botes motorizados, câmaras frigoríficas, condutores experientes, refeições com pratos típicos regionais, além daqueles feitos com peixes capturados (SUDRÉ, 2012).

Os roteiros que os barcos-hotéis realizam abrangem três principais segmentos: passeio ecológico, turismo de natureza e pesca esportiva. Vale ressaltar que o "ecoturismo" acontece apenas na ausência da pesca, portanto não é realizado como opção no roteiro, mas como alternativa para turistas (SUDRÉ, 2012).

Na década de 90, políticas de desenvolvimento regional foram implantadas em Cáceres; esses programas apresentaram vários projetos sendo um deles o da hidrovia Paraguai-Paraná para implementação do sistema fluvial, abrangendo cinco países da Bacia do Prata (porto em Cáceres) para escoamento da soja (SOUZA, 2004).

A princípio, a hidrovia teria início no porto de Cáceres e faria ligação até Nueva Palmira, no Uruguai. No entanto, em virtude de características (meandramento) próprias de um trecho crítico da hidrovia, ela iniciaria no porto instalado na fazenda Santo Antônio das Lendas, lugar, pertencente à área de estudo deste trabalho.

O porto receberia a denominação de Porto Morrinhos, por localizar-se próximo à serra de mesmo nome, e está projetado para servir como terminal de carga para soja, açúcar e madeira, e descarga de trigo e sal importados. Segundo a ACBL (2000), o local selecionado para a implantação do futuro Porto, denominado sítio 2, apresenta condições menos impactantes ao meio ambiente, como disponibilidade de 
material para aterro hidráulico, estabilidade do leito do rio Paraguai e da sua margem direita, canal alternativo e localização (atrás de 200 m de mata ciliar).

Mesmo possuindo tais vantagens, ainda assim provocaria impactos no local. A dragagem do canal secundário, denominado baía do Tocá, por exemplo, poderá alterar toda a dinâmica do ecossistema da região, promovendo alteração na qualidade da água, do ar e do solo, além de mudanças na paisagem.

A implantação do Porto de Morrinhos e, consequentemente, da Hidrovia Paraguai Paraná na região de Cáceres ainda está em discussão. Após Estudo de Impactos Ambientais e posterior relatório, verificou-se que os resultados apresentados carecem de dados e informações para determinar as intervenções físicas passíveis de serem executadas. As autoridades ambientais brasileiras encontraram, portanto, razões para incerteza ao analisar os resultados do estudo e foram levadas à posição de gradualismo e cautela quanto à definição das obras na Hidrovia (ZUGAIB, 2006).

É cada vez mais frequente a dragagem no trecho entre Cáceres e a fazenda Santo Antônio das Lendas. Anualmente, vários trechos estão sofrendo com o assoreamento e a diminuição da profundidade. Sendo observado no período de estiagem.

A atividade de dragagem consiste em aprofundar periodicamente pontos altos do canal navegável (MARINHA DO BRASIL, S/D). A resolução CONAMA 344/2004 prevê a necessidade de dragagem para garantir a condição de navegação em corpos hídricos, porém faz algumas ressalvas, como avaliar o tipo de material que está sendo dragado e as condições nas quais se encontram os sedimentos que são retirados do leito dos corpos d'água, elementos estes que possuem grande potencial de carregar contaminantes.

Essa atividade pode ser realizada de três formas: a dragagem inicial, a de manutenção e a ambiental (TEIXEIRA, 2009). No rio Paraguai, executa-se a segunda especificamente. O mesmo autor ainda diz que a dragagem de manutenção é utilizada para a remoção de sedimentos que se depositaram recentemente no rio.

CEBRAC (2000) ressalta que a operação de dragagem se torna repetitiva e sem fim, pois modifica o leito do rio, alterando suas variáveis dependentes de processos morfológicos e transformando temporariamente seu equilíbrio sedimentológico. Depois do escoamento, as variáveis são restauradas. Assim quanto mais se opera a dragagem, mais rápida torna-se a velocidade do fluxo da água, intensificando a erosão das margens côncavas e, consequentemente, a deposição nas margens convexas, o que altera a morfologia do canal e sua dinâmica natural. Ainda destacam que o trecho do rio Paraguai entre Cáceres e Porto Murtinho é extremamente sensível a intervenções antrópicas, dentre elas a dragagem.

A dragagem realizada entre a foz do rio Jauru e a fazenda Santo Antônio das Lendas é do tipo hidráulica, utilizando as dragas de sucção para implementação dessa atividade. Segundo Teixeira (2009), essas dragas removem e transportam o sedimento na forma líquida, sendo mais adequadas para a remoção de areia e silte pouco consolidado. São, em geral, bombas centrífugas, acionadas por motores a diesel ou elétricos, montadas sobre barcas e que descarregam o material dragado através de tubulações que variam de $0,15 \mathrm{~m}$ a 1,2 $\mathrm{m}$ de diâmetro, mantidas sobre a água através de flutuadores. A bomba produz vácuo na 
entrada da tubulação, forçando água e sedimento a entrarem através dos canos. Essas dragas não podem operar com material que contenha grandes pedras.

No trecho de estudo, a empresa responsável pela dragagem de manutenção, a AHIPAR Administração da Hidrovia do Paraguai - inicia suas atividades no período de estiagem, entre agosto e outubro, após a autorização da Marinha, realizando a dragagem em todos os pontos necessários. Apenas uma draga é utilizada, a qual vai abrindo o canal, percorrendo os passos. Vale ressaltar que todo o material dragado é depositado nas margens do rio.

No trecho em estudo, existem vários pontos críticos, são justamente os locais de menores profundidades do rio, onde são usadas dragas para aumentar a profundidade do leito, adequando o rio às embarcações de grande porte, principalmente turísticas, como os barcos hotéis.

Durante trabalho de campo, pode-se observar a atuação das dragas em trechos críticos, como próximo ao Hotel Baiazinha, denominado Passo Baiazinha e no passo denominado Corixão, próximo à baía das éguas.

Pesquisas acerca da dragagem no Alto Paraguai ressaltam as consequências dessa atividade para a dinâmica fluvial do rio. Os estudos realizados por Cebrac (2000) destacam, em relatório realizado após expedição no rio Paraguai de Cáceres até Porto Murtinho, que existem vários pontos críticos do rio Paraguai, como o trecho entre Cáceres e Bracinho, abrangendo a área de estudo deste trabalho de pesquisa.

Zugaib (2006) ressaltou em seu trabalho que a atividade de dragagem tornou-se mais intensa depois que o projeto da hidrovia Paraguai Paraná (HPP) iniciou suas atividades; porém, mesmo não existindo mais trafego de comboios de carga no rio Paraguai entre Cáceres e Corumbá há cerca de 06 anos, devido à decisão judicial ambiental, as consequências podem ser observadas até os dias atuais, podendo ter relação com a navegação desses grandes comboios no período em que estiveram presentes no rio.

Estudos realizados no rio Paraguai, como os evidenciados por Cebrac (2000) e Lima et al. (2007), que abrangem a área de estudo, evidenciaram que o trecho em questão apresenta vários obstáculos à navegação. O transporte de comboios pode ter contribuído, junto com o tipo de uso do solo no entorno da área de estudo, para o aumento do aporte de sedimentos no rio, trazendo consequências como: alteração do canal, assoreamento, desbarrancamento e perda de mata ciliar.

Souza (2004), em trabalho realizado entre Cáceres e a Reserva do Taiamã, verificou que o aumento da carga de sedimentos pode ser atribuído a alguns fatores, dentre eles a dragagem e a própria carga de sedimentos provenientes do rio Jauru, que é um dos principais contribuintes do rio Paraguai.

Assim, a dragagem de manutenção é uma das ações antrópicas que ultimamente estão tornando-se mais frequente no rio Paraguai, podendo trazer sérias consequências a médio e longo prazo para todo o ecossistema aquático e para a dinâmica fluvial do rio, além da própria morfologia do canal. Isso dificulta, inclusive, a sinalização no rio pela Marinha; pois, constantemente, as placas devem ser substituídas, visto que os sedimentos estão sendo remobilizados e depositados novamente, aumentando a quantidade de sedimentos em suspensão, inclusive alterando a própria qualidade da água. 
Segundo Castro e Almeida (2012), é unânime entre vários autores que a dragagem de rios traz impactos negativos ao ambiente, sejam eles diretos ou indiretos. Os principais problemas citados são: alteração das condições hidráulicas e sedimentológicas do escoamento, com possível alteração dos padrões de circulação e mistura da água; salinidade e turbidez; poluição por substâncias tóxicas existentes no material de dragagem, sua suspensão e movimentação durante a atividade, com alteração da qualidade da água (turbidez), impactos diretos sobre habitats da fauna e flora aquática.

Lima e Oliveira (2007) realizaram um levantamento do volume de material dragado no rio no trecho entre Cáceres e Paratudal, no período de 1990 a 2005, evidenciado vários trechos críticos ao longo dos anos. O intuito das atividades de dragagem foi a manutenção da hidrovia (tabela1).

Tabela 1: Volume de material dragado anualmente entre os anos de 1990 e 2005.

\begin{tabular}{c|c|c|c|c|c|c|c}
\hline \multirow{2}{*}{ Trechos/Localização } & \multicolumn{7}{|c}{ Volume dragado $\left.\mathbf{( m}^{\mathbf{3}}\right)$} \\
\cline { 2 - 8 } & \multirow{2}{*}{1990} & 1993 & 1997 & 1999 & 2001 & 2003 & 2005 \\
\hline Jauru Velho & & & & 8.010 & 31.659 & 19.249 & 14.376 \\
\hline Pote & & & 4.554 & 1.775 & 6.937 & 9.636 & 24.412 \\
\hline Soldado & & 4.800 & 8.000 & 18.125 & 8.094 & 9.310 & 14.896 \\
\hline Baiazinha & 4.830 & 3.120 & 23.000 & 7.991 & 19.009 & 22.073 & 15.120 \\
\hline Corixão & & & 22.300 & 29.297 & 6.599 & 26.439 & 16.612 \\
\hline Baía das Éguas & & & 6.500 & 1.1101 & 9.409 & 27.124 & 18.868 \\
\hline
\end{tabular}

Fonte: Adaptado de Lima et al. (2007).

Todos os trechos representados na tabela1 estão dentro da área de estudo deste trabalho. A princípio, Lima e Oliveira (2007) ressaltam que as dragagens eram esporádicas. Porém, percebe-se que o passo Baiazinha sempre foi crítico, sendo que desde 1990 as atividades de dragagem de manutenção estavam presentes. Percebe-se que, em alguns anos (de 1997, 1999 e 2003) ocorreu maior dragagem de sedimentos.

Dados mais recentes disponibilizados pela empresa responsável pela dragagem sugerem que, apesar de o material dragado no rio Paraguai apresentar números oscilantes, a quantidade vem aumentando ao longo dos anos. Na tabela 2, verifica-se o volume de material dragado no trecho entre a foz do rio Jauru e a fazenda Santo Antônio das Lendas.

No período entre 2005 a 2015, registrou-se um aumento da carga de sedimentos dragada na calha do rio Paraguai no trecho estudado, houve aumento significativo de material dragado no rio Paraguai em vários pontos. Os trechos que tiveram maior remoção de sedimentos foram Soldado Superior, Ilha do Barranco Vermelho e Ilha do Barranco Vermelho (tabela 2).

Tabela 02: Volume de material dragado nos passos entre a foz do rio Jauru e a fazenda Santo Antônio das Lendas entre 2005 e 2015.

\begin{tabular}{c|c|c|c|c|c|c|c|c}
\hline \multirow{2}{*}{ Trechos/Localização } & \multicolumn{7}{|c|}{ Volume Dragado $\left(\mathbf{m}^{\mathbf{3}}\right)$} \\
\cline { 2 - 9 } & $\mathbf{2 0 0 5}$ & $\mathbf{2 0 0 6}$ & $\mathbf{2 0 0 7}$ & $\mathbf{2 0 0 8}$ & $\mathbf{2 0 1 2}$ & $\mathbf{2 0 1 3}$ & $\mathbf{2 0 1 4}$ & $\mathbf{2 0 1 5}$ \\
\hline Jauru Velho & 14.376 & & 32.472 & 19.800 & 11.174, & 23.886 & 37.355 & \\
\hline Passo do Pote & 24.412 & & 25.420 & & 10.527. & 8.202 & 10.665 & 20.373 \\
\hline Passo Tucum & 14.458 & & 30.488 & & 9.814 & 15.388 & 13.468 & 25.909 \\
\hline Soldado Superior & & 6.225 & 11.571 & 20.000 & 5.161 & 6.315 & 12.795 & 43.217 \\
\hline Soldado Inferior & 14.896 & 3.352 & 13.086 & 14.300 & 5.866 & 8.912 & 9.255 & 18.875 \\
\hline Ilha do Barranco Vermelho & & 13.011 & & & 17.654 & $23.177,10$ & 33.784 & $\mathbf{3 2 . 5 1 1}$ \\
\hline Baiazinha & $\mathbf{1 5 . 1 2 0}$ & 19.541 & 22.788 & 16.940 & 6.893 & $19.379,97$ & 28.818 & 44.477 \\
\hline
\end{tabular}




\begin{tabular}{c|c|c|c|c|c|c|c|c}
\hline Corixão & 16.612 & 9.600, & 5.104 & 13.000 & 5.453 & $14.724,19$ & & 15.101, \\
\hline Baia das Éguas & 18.868 & 15.415 & 11.974 & & 4.867 & & & 28.381 \\
\hline
\end{tabular}

Entre os anos de 2012 e 2015, os dados relativos à medição da altura do rio Paraguai disponibilizados pela Marinha demonstram que o rio, nos períodos de estiagem e cheia, obteve uma média anual da altura de 2,84m, 3,51m, 3,32m, 2,55m nos anos de 2015, 2014, 2013 e 2012, respectivamente. Logo, pode-se inferir que, no período de cheias dos anos de 2012 e 2015, o rio apresentou um menor volume de água. Então, nesses anos, o volume de material dragado pode estar associado à intensificação do uso da terra no entorno do corredor fluvial.

Os sedimentos dragados são colocados nas margens do rio Paraguai, no período estiagem; na época de cheias, porém, essa carga de sedimentos retorna ao leito. Então, o aumento do material dragado, observado a partir de 1997 em trechos críticos na área de estudo, pode ter relação com as atividades de uso no entorno do corredor fluvial, como a pecuária, juntamente com o aumento do índice pluviométrico percebido no mesmo período.

\section{Ocupação e uso atual das margens do rio Paraguai entre a foz do rio Jauru e a fazenda Santo Antônio das Lendas, no município de Cáceres}

O segmento que compreende a área de estudo possui cerca de $41 \mathrm{~km}$ de extensão. Nesse trecho, o rio Paraguai possui controle estrutural na sua margem esquerda, devido à sua formação litológica, resistente a processos erosivos. Na margem direita, há uma faixa de planície de inundação.

Ao longo do corredor fluvial, entre a foz do rio Jauru e a fazenda Santo Antônio das Lendas, na baía Morrinhos, grande parte da mata ciliar na margem direita do rio Paraguai encontra-se preservada, sendo poucos os trechos com ocupação antrópica. Na margem esquerda, registra-se vários segmentos ocupados por fazendas. As áreas preservadas na margem esquerda são as serras e planícies de inundação permanente ou temporária. O trecho estudado é ocupado por várias fazendas com as sedes próximas do rio; hotéis, pousadas, ranchos e pesqueiros (tablados). Verificou-se e existência de várias estradas e trilhas para facilitar o acesso.

Com relação às estradas sem pavimentação, essas vias são multiplicadoras do efeito de carreamento superficial de matérias cujo destino são córregos e, consequentemente, os rios onde desaguam, pois são responsáveis pelos maiores índices de perda de solo (ESPÍNDOLA et al., 2003). Portanto, essas estradas, se mal planejadas, sejam elas pavimentadas ou não, podem acarretar sérios danos ambientais, podendo comprometer toda a dinâmica da bacia.

Nos mapas relativos à evolução do processo de uso no entorno do rio Paraguai, no trecho entre a foz do rio Jauru e a fazenda Santo Antônio das Lendas, no período entre 1984 a 2015, ou seja, 31 anos, é possível verificar que houve aumento expressivo da área desmatada na margem esquerda; porém, na margem direita, houve a recomposição da vegetação (tabela 3 e figura 2). 

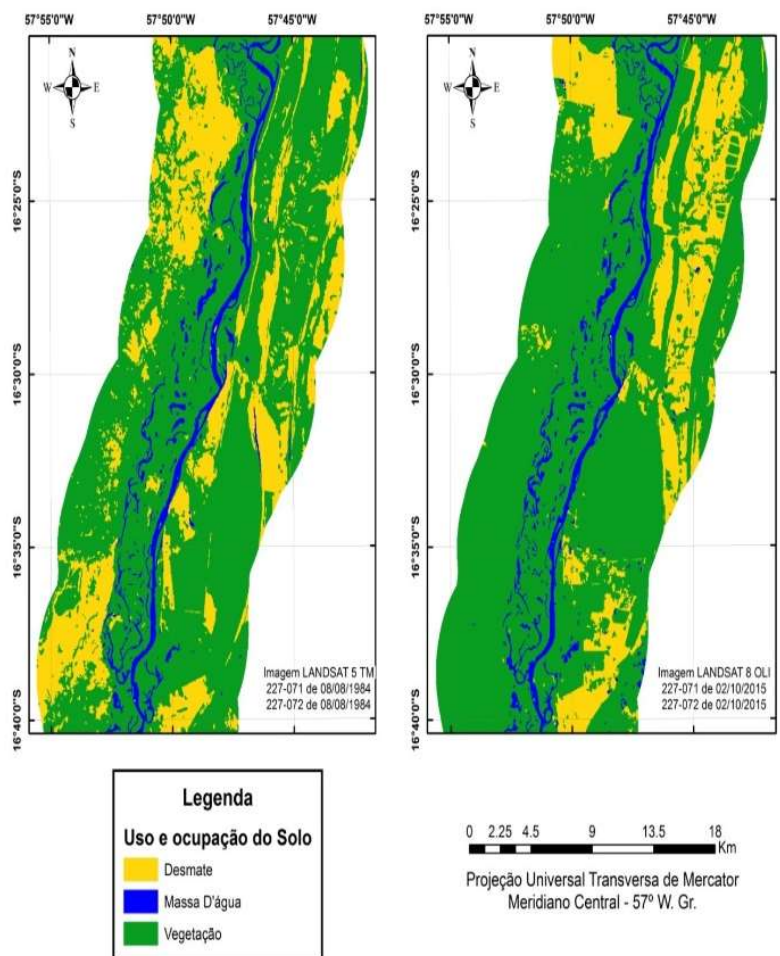

Figura 2: Mapa de evolução do uso da terra entre os anos de 1984 e 2015 do trecho de estudo.

Tabela 03: Evolução do uso e ocupação na área de estudo em 31 anos.

\begin{tabular}{cccccc}
\hline & Uso do Solo - 1984 & & \multicolumn{3}{c}{ Uso do Solo-2015 } \\
Vegetação & Desmate & Massa D'Água & Vegetação & Desmate & Massa D'Água \\
501,06 & 159,33 & 41,20 & 533,60 & 122,18 & 45,78 \\
$71,42 \%$ & $20,71 \%$ & $5,78 \%$ & $76,06 \%$ & $17,41 \%$ & $6,53 \%$ \\
\hline
\end{tabular}

Na margem esquerda, verifica-se que a área de desmate teve um aumento expressivo. Em 1984 representava $78,63 \mathrm{~km}^{2}$ da área total e passou para $92,59 \mathrm{~km}^{2}$ em 2015. Isso pode ter relação com o aumento de áreas destinadas à pastagem e com a introdução do cultivo de soja (tabela 3). Na margem direita, na faixa de planície de inundação, a área vegetada correspondia a 257km² em 1984; em 2015, a área com vegetação aumentou para $302,28 \mathrm{~km}^{2}$, indicando que houve recuperação de área vegetada (Figura 2 e Tabelas 4).

Tabela 4: Evolução da área desmatada no intervalo de tempo de 31 anos nas margens esquerda e direita do Paraguai.

\begin{tabular}{cc|cc}
\multicolumn{4}{c}{ Tabela 4: Evolução da àrea desmatada no intervalo de tempo de 31 anos nas margens esquerda e direita do Paraguai. } \\
\hline \multirow{2}{*}{ Vegetação } & Ano & Margem Esquerda & Margem Direita \\
& 1984 & $\mathrm{~km}^{2}$ & 257,00 \\
\multirow{2}{*}{ Desmate } & 2015 & 244,06 & 302,28 \\
& 1984 & 231,32 & 80,7 \\
\hline
\end{tabular}

Assim, depois de seca intensa, a vegetação pode recuperar-se novamente. O monitoramento sobre a vegetação no Alto Paraguai, realizado de 2002 até 2014 pela WWF em parceria com outras instituições, demonstra que a região da margem direita que abrange a área de estudo deste trabalho é coberta por savana arborizada (cerrado), sendo áreas próximas às margens do rio, vegetação típica com influência fluvial.

Nota-se no mapa que a maior parte da área na margem esquerda, que abrange a planície de inundação que se apresenta como desmatada, possui um padrão irregular nas bordas, demonstrando que ali, no ano de 1984, a vegetação foi retirada e, em 2015, ela foi recuperada. Em alguns pontos verifica-se 
padrão diferente da área desmatada, pois nota-se um padrão com linhas retas, típico de área para implantação de pecuária, fácil de ser cercada.

Ainda na margem direita, no ano de 1984, observou-se que a região com supressão de vegetação contorna várias massas de água, como a área próxima ao rio Jauru. Provavelmente são áreas nas quais encontram-se atividades como, por exemplo, pecuária extensiva. Nessa mesma área, encontra-se uma fazenda que, nos últimos 10 anos, vêm destacando-se na criação de gado regionalmente. Tal fazenda pertence ao grupo Cometa, de propriedade do atual prefeito de Cáceres, abrangendo uma vasta área do trecho de estudo, desde área próxima ao rio Jauru estendendo-se até as proximidades dos limites da Fazenda Descalvados.

Além disso, nessa mesma área, encontram-se várias estradas secundárias que dão acesso via terrestre às margens do rio e às fazendas, o que pode justificar o desmate na região. Vários trabalhos também indicam que a bacia do rio Jauru se encontra frágil ambientalmente, devido às atividades desenvolvidas na bacia, como exemplo, a pecuária. Destacam-se trabalhos de Neves et al. (2011) e Andrade et al. (2012).

Com a recuperação de área vegetada, houve um aumento de massa de água, que evoluiu de 5,78\%, em 1984, para 6,53\% em 2015. Logo, um maior volume de água está abastecendo o lençol freático e, consequentemente, toda a bacia.

Na margem esquerda, verifica-se que a área de desmate teve um aumento expressivo, fato que pode estar relacionado com as atividades de pecuária desenvolvidas nos dias de hoje e, mais recentemente, com a agricultura, o cultivo de soja. Nessa região, por exemplo, encontra-se a fazenda Ressaca, que possui um rebanho com aproximadamente 26 mil cabeças de gado, destinados ao comércio. Esses animais são mantidos em cerca de 34 mil hectares de terra.

Em 2014, a fazenda iniciou o Sistema de Integração Lavoura-Pecuária - ILP, destinando cerca de 1.055 hectares ao cultivo de soja, tornando-se pioneira na região, visto que está produzindo soja em local fora do mapa nacional de oleoginosa. Já no ano de 2015, foram coletadas entre 56 e 73 sacas por hectare, sendo esse índice comemorado pelos produtores. 0 plano desses agricultores é aumentar a área cultivada para 5 mil hectares até a safra de 2016/2017. No ano de 2015, existia uma relação de 1,5 unidade animal (UA) por hectare. Segundo a previsão, esse índice pode chegar em 5 UA.

O Sistema de Integração Lavoura Pecuária - ILP consiste nas atividades de diversificação, rotação, consorciação e/ou sucessão das atividades de agricultura e de pecuária dentro da propriedade rural, de forma harmônica. Isso permite a consolidação de um sistema único, o qual traz benefícios para ambas as áreas, possibilitando que o solo seja explorado economicamente durante todo o ano ou, pelo menos, na maior parte dele (ALVARENGA; DOCE, 2005).

Apesar dos benefícios desse tipo de atividade, vários autores chamam atenção para os possíveis efeitos negativos para o meio ambiente que podem ser originados pelo processo. Albuquerque et al. (2001) realizou um trabalho sobre os efeitos da integração lavoura-pecuária nas propriedades físicas do solo e sobre as características da cultura do milho numa região de Santa Catarina. Verificou que a compactação imposta 
pela integração lavoura-pecuária reduziu os macroporos e, consequentemente, a condutividade hidráulica saturada, aumentando a resistência à penetração de raízes no solo.

Cardoso et al. (2009), em trabalho realizado na região pantaneira, verificou que a substituição da floresta nativa por pastagem cultivada reduz os teores de carbono do solo, sendo o carbono microbiano o atributo mais sensível às alterações no solo. Então, cabe ressaltar aqui que, apesar dos benefícios, faz-se necessário um estudo desse tipo de atividade inovadora e, de certa forma, recente no trecho estudado por este trabalho, visto que essa área possui peculiaridades, exigindo um olhar mais atento às possíveis consequências de toda e qualquer ação ali desenvolvida.

Como a pecuária está muito presente, verificou-se que dados do IBGE sobre o efetivo bovino, por exemplo, demonstram um aumento no número de 364.438, no ano de 1990, para 1.024.196 no ano de 2014, no município de Cáceres. Logo, esses dados corroboram com a ideia de que a pecuária se encontra em constante crescimento e que como houve um aumento do desmate na margem esquerda do trecho de estudo desta pesquisa. Pode-se estabelecer relação, afirmando que isso ocorreu para que a vegetação nativa pudesse ser substituída por pastagem.

Assim, como a pecuária está presente e em constante crescimento, pode-se inferir que a área a ser desmatada aumentou para o plantio de pasto. Logo, o solo fica exposto e vulnerável à erosão hídrica, aumentando a quantidade de sedimentos transportados pelo escoamento superficial que chega ao leito do rio, aumentando, assim, o assoreamento.

Segundo Petry et al. (2011), a pecuária é uma atividade econômica tradicional, tanto na região das cabeceiras quanto na planície pantaneira. Atualmente, a quantidade de gado por hectare vem aumentando em grandes propriedades, devido à melhoria das pastagens plantadas e à genética dos rebanhos. Isso, associado ao manejo incorreto do gado e das pastagens, pode ocasionar impactos, como permitir que os animais bebam diretamente nos cursos d'água e o sobrepastejo, levando a exposição do solo à ação erosiva das chuvas e, consequentemente, à sua degradação. O processo erosivo em larga escala resulta na sedimentação das águas e assoreamento dos rios e córregos.

Como citado anteriormente, nos dias de hoje, está sendo desenvolvido o plantio de soja na margem esquerda do rio Paraguai pela fazenda Ressaca. Dados do IBGE de 1990 sobre o plantio de soja no município de Cáceres, demonstram que o cultivo do produto está destacando-se na região. Em 1990, tinha-se apenas 100 hectares de terra destinadas ao plantio de soja; enquanto em 2014, esse número subiu para 4150 hectares. É um aumento bastante expressivo, subtendendo-se que cada vez mais vegetação nativa está sendo destruída para a monocultura.

Percebe-se, portanto, que diversas atividades realizadas no trecho estudado evoluíram nas últimas décadas. Agricultura, pecuária e transporte fluvial representam um conjunto que vem, gradativamente, provocando mudanças na paisagem natural da região.

Apesar da ocorrência de serras na margem esquerda, a ocupação acontece nos vales e próxima da calha do rio Paraguai. As áreas que foram mais desmatadas encontram-se nas fazendas Ressaca, Barranco 
Vermelho, Santo Antônio das Lendas e próximas ao Hotel Baiazinha, sendo que nesta última, provavelmente, a área vegetada foi suprimida devido à construção de um aeroporto próximo ao hotel.

Ao longo da margem esquerda, verificou-se a presença de estradas vicinais sem pavimentação que dão acesso às fazendas e trilhas. As estradas servem de ligação das propriedades rurais. A proposta atual é expandir a rodovia MT 343 até o Porto de Morrinhos e pavimentá-la.

Segundo Petry et al. (2011), estradas têm grande potencial de impacto sobre os recursos hídricos; principalmente as secundárias, não pavimentadas e abertas, as quais não possuem sem os cuidados técnicos necessários para evitar a erosão, o barramento ou a alteração dos cursos d'água. Além disso, essas vias podem ser importantes vetores de transporte de sedimentos e de contaminantes.

CEBRAC (2000) reforça que a construção de estradas sobre a planície alagável pode afetar as condições de circulação das águas nos períodos de cheia, alterando as condições naturais do funcionamento hídrico.

Além da pecuária e da agricultura desenvolvidas no corredor fluvial, destacam-se também o turismo e a pesca. Tais atividades atraem pessoas durante todo o ano ao Pantanal Norte, sendo o turismo de contemplação presente o ano todo e a pesca apenas no período que antecede à piracema. As atividades pesqueiras são realizadas pelos turistas dos barcos hotéis, barcos e nos barrancos ao longo do perfil longitudinal do rio Paraguai. Essas atividades provocam perturbação ambiental.

A pesca embarcada tem os barcos hotéis como principais atuantes nesse tipo de atividade. Tais embarcações possuem estrutura para acomodar vários passageiros e recebem turistas de todo o Brasil. Esses barcos navegam pelo Rio Paraguai desde Cáceres até a Reserva do Taiamã, podendo ficar ancorados próximos à foz do Jauru, fazenda Barranco Vermelho, Morrinhos, e até atravessarem a reserva em algumas situações. Portanto, o trecho de estudo deste trabalho possui um fluxo contínuo das mais variadas embarcações, que incluem os barcos hotéis e as embarcações menores, que dão apoio a esses veículos.

Assim, pode-se inferir que, devido ao fluxo constante de embarcações, esses barcos podem estar contribuindo para que ocorra a intensificação do processo de erosão das margens, devido às ondas provocadas pela movimentação dos veículos.

Em alguns pontos foram construídos ranchos e tablados no rio, contribuindo com processos de supressão de vegetação, deixando o solo exposto, aumentando o escoamento superficial e, consequentemente, o aporte de sedimentos na calha do rio. Apesar de serem fontes pontuais, o conjunto de todas elas contribui para uma perturbação de toda a bacia.

Nota-se também a presença de hotéis à beira do rio Paraguai, os quais provocam um desmate local, como é o caso do hotel Baiazinha e da pousada Barranco Vermelho. A primeira possui estrutura para atender demanda de turistas internacionalmente.

\section{CONSIDERAÇÕES FINAIS}

Desde a ocupação iniciada às margens do rio Paraguai pelos indígenas, estudos demonstram que todo esse processo possui uma interdependência com a navegação no rio. Nesse contexto, surgiram as 
fazendas históricas ao longo do corredor fluvial, como a Ressaca, Barranco Vermelho e Santo Antônio das Lendas.

Atualmente, o cenário é marcado por atividades que possuem um grande potencial para provocar desequilíbrios ambientais, caso o manejo desses processos não for adequado às peculiaridades da área de estudo. Atividades de destaque e muito marcantes são a pecuária e cultivo de soja. Além dessas, a navegação na área é contínua devido, ao turismo e a pesca.

A pesca é um atrativo para que pescadores construam ranchos e tablados à beira rio, o que foi verificado ao longo do corredor fluvial do trecho de estudo. O fluxo de embarcações, dos mais variados tamanhos e velocidades, vem provocando, gradativamente, mudanças na dinâmica fluvial do rio Paraguai e na sua própria morfologia, pois alteram o aporte de sedimentos no rio, provocando assoreamento e erosão das margens.

Pelo fato de o rio Paraguai possuir grande potencial turístico, é corriqueiro ver barcos hotéis navegando no trecho em estudo. Em época de estiagem, muitas dessas embarcações não conseguem navegar pelos passos críticos identificados na área, tornando-se limitadas em sua navegabilidade. Assim, constantemente ocorre a dragagem, para manter as atividades turísticas e, em virtude disso, econômicas, em pleno funcionamento.

Dados revelaram que o aumento do volume de material dragado nos últimos anos tem relação não só com o índice pluviométrico, mas também com atividades como a pecuária e cultivo de soja, que são bastante expressivas na região, sendo a agricultura algo mais recente. Recomendam-se estudos mais precisos relacionados à composição desses sedimentos, visto que possuem potencial de carregar substâncias nocivas à bacia, comprometendo todo o ecossistema aquático.

Verificou-se, também, que, na planície de inundação, entre os anos de 1984 e 2015, houve recuperação de vegetação, diminuindo a área desmatada. Isso pode ser atribuído à própria adaptação da vegetação da área de planície no Pantanal, a qual é suprimida nos períodos de seca, aliada à criação extensiva de gado. A vegetação recupera-se a cada ciclo de cheias.

\section{REFERÊNCIAS}

ACBL. Estudo de Impacto Ambiental (EIA) do Porto de Morrinhos, município de Cáceres, MT. Consorcio Walm Ambiental, 2000.

ALMEIDA. F. G.; PEREIRA, L. F. M.; O papel da distribuição e da gestão dos recursos hídricos no ordenamento territorial Brasileiro. In: ALMEIDA, F. G; SOARES, L. A. A.. Ordenamento territorial: coletânea de textos com diferentes abordagens no contexto brasileiro. Rio de Janeiro: Bertrand Brasil, 2009.

ALVARENGA, R. C; DOCE, M. A. Integração lavoura e pecuária. Sete Lagoas: Embrapa Milho e Sorgo, 2005.

ANDRADE, L. N. P. S.. Uso e ocupação da bacia hidrográfica do rio Jauru. In: SOUZA, C. A.; SOUSA, J. B.; ANDRADE, L. N. P. S.. Bacia hidrográfica do rio Jauru, Mato Grosso: dinâmica espacial e impactos associados. São Carlos: Rima Editora, 2012.
BINDANDI, N. M.. Evolução da navegação, morfologia e sedimentação no rio Paraguai no município de Cáceres, Mato Grosso, Brasil. 2014. 139 f. Dissertação (Mestrado) Universidade Estadual do Mato Grosso, Cáceres, 2014.

BRASIL. Ministério do Meio Ambiente. Resolução CONAMA no 344, de 25 de março de 2004. Estabelece as diretrizes gerais e os procedimentos mínimos para a avaliação do material a ser dragado em águas jurisdicionais brasileiras, e dá outras providências.

BRASIL. Marinha do Brasil. Navegação fluvial: navegação eletrônica e em condições especiais.

CARDOSO, E. L.. Atributos biológicos indicadores da qualidade do solo em pastagem cultivada e nativa no Pantanal. In: Pesquisa Agropecuária Brasileira, Brasília, v.44, n.6, p.631-637, 2009. 
CASTRO, S. M.; ALMEIDA. J. R. Dragagem e conflitos ambientais em portos clássicos e modernos: uma revisão. Soc. \& Nat., Uberlândia, v.24, n.3, p.519-534, 2012.

CEBRAC. Realidade Pantanal: retrato da navegação no Alto rio Paraguai. Relatório final de expedição científica no trecho do rio Paraguai entre Cáceres e Porto Mortinho. Brasília: 2000.

CHAVES, O. R.. Império português: o marco de Jauru e a povoação fronteiriça de Vila Maria do Paraguai, século XVIII. In: CHAVES, O. R.; ARRUDA, E. F.. História e memória de Cáceres. Cáceres: UNEMAT, 2011.

ESPINDOLA, E. L. G.. Caracterização física, química e biológica da água do rio Mogi Guaçu. In: BRIGANTE, J.; ESPINDOLA, E. L.. Limnologia fluvial: um estudo no rio Mogi Guaçu. São Carlos: Rima, 2003.

GUERRA, A. J. T.. Encostas e a questão ambiental. In: CUNHA, S. B.; GUERRA, A. J. T.. A questão ambiental: diferentes abordagens. Rio de Janeiro: Bertrand Brasil, 2003.

IBGE, Instituto Brasileiro de Geografia e Estatística. Manual técnico de geomorfologia. Rio de Janeiro: IBGE, 2009.

LIMA, C. A. N.; OLIVEIRA, I. G.. Relação entre a intensificação do uso do solo e o aumento das dragagens na hidrovia do rio Paraguai. In: Simpósio Brasileiro de Sensoriamento Remoto, 13. Anais. Florianópolis: INPE, 2007.

NEVES, S. M. A. S.. Estimativa da perda de solo por erosão hídrica na bacia hidrográfica do rio Jauru/MT. Soc. \& Nat., Uberlândia, v.23, n.3, 2011.

PETRY, P.. Análise de risco ecológico da Bacia do Rio Paraguai: Argentina, Bolívia, Brasil e Paraguai. Brasília: WWF-Brasil, 2011.

REBOUÇAS, A. C.. Água doce no Brasil e no mundo. In: REBOUÇAS, A. C.; BRAGA, B.; TUNDISI, J. G.. Água doce no Brasil: capital ecológico, uso e conservação. 3 ed. São Paulo: Escrituras, 2006.
SILVA, R. V.. Uso e ocupação da margem esquerda do rio Paraguai e a percepção ambiental de usuários do município de Cáceres, Mato Grosso. Dissertação (Mestrado em Ciências Ambientais) - Universidade Estadual do Mato Grosso, Cáceres, 2011.

SILVA, A.. Avaliação da erosão na margem direita do rio Paraguai a jusante da praia do Julião município de Cáceres, MT. Revista Geográfica Acadêmica, v.1, n.1, 2007.

SILVEIRA, M. A. T.; ZIBETTI, R. A.. O turismo náutico como vetor de desenvolvimento turístico da região hidrográfica do Paraguai: desafios e oportunidades. In: SEMINÁRIO DE TRANSPORTE E DESENVOLVIMENTO HIDROVIÁRIO INTERIOR, 9. Anais. Manaus: 2015.

SOUZA, C. A.. Dinâmica do corredor fluvial do rio Paraguai entre a cidade de Cáceres e a Estação Ecológica da llha de Taiamã, MT. Tese (Doutorado em Geografia) - Universidade Federal do Rio de Janeiro, Rio de Janeiro, 2004.

SOUZA, C. A.. Bacia hidrográfica do rio Jauru e seus afluentes. In: SOUZA, C. A.. Bacia hidrográfica do rio Jauru, Mato Grosso: dinâmica espacial e impactos associados. São Carlos: Rima, 2012.

SUDRÉ, S. G. S.. O turismo no rio Paraguai em Cáceres, pantanal mato-grossense, Brasil. Dissertação (Mestrado em Ciências Ambientais) - Universidade Estadual do Mato Grosso, Cáceres, 2012.

SUGUIO, K.; BIGARELLA, J. J.. Ambientes fluviais. 2 ed. Florianópolis: UFSC, 1990.

TEIXEIRA, L. S.. Estudo das propriedades químicas dos rejeitos da dragagem do porto novo para utilização como solo fabricado para fins agrícolas. Dissertação (Mestrado em Engenharia Oceânica) - Universidade Federal do Rio Grande, Rio Grande, 2009.

ZUGAIB, E.. A hidrovia Paraguai-Paraná e seu significado para a diplomacia sul-americana do Brasil. Brasília: FUNAG, 2006.

A CBPC - Companhia Brasileira de Produção Científica (CNPJ: 11.221.422/0001-03) detém os direitos materiais desta publicação. Os direitos referem-se à publicação do trabalho em qualquer parte do mundo, incluindo os direitos às renovações, expansões e disseminações da contribuição, bem como outros direitos subsidiários. Todos os trabalhos publicados eletronicamente poderão posteriormente ser publicados em coletâneas impressas sob coordenação da Sustenere Publishing, da Companhia Brasileira de Produção Científica e seus parceiros autorizados. Os (as) autores (as) preservam os direitos autorais, mas não têm permissão para a publicação da contribuição em outro meio, impresso ou digital, em português ou em tradução. 